\title{
TRADE AND GROWTH IN A TWO-COUNTRY MODEL WITH HOME PRODUCTION AND UNEVEN TECHNOLOGICAL SPILLOVERS*
}

\author{
by \\ LUIGI BONATTI \\ University of Trento \\ and \\ GIULIA FELICE ${ }^{\dagger}$ \\ University of Milan and Centro Studi Luca d'Agliano
}

\begin{abstract}
We develop a two-country growth model distinguishing between a market sector producing services that can also be home produced and a market sector producing goods without home-produced substitutes. The former is a technologically 'stagnant' sector, while the latter is subject to learning-by-doing and technological spillovers. This distinction coincides in the model with the distinction between the sector producing nontradables and the sector producing internationally tradable goods. We study how differentials in labor tax rates across countries influence the mix of tradable and non-tradable goods that characterizes the market output of each country, thus affecting their bilateral trade balance and growth rates.
\end{abstract}

\section{INTRODUCTION}

There are four stylized facts that emerge among others when comparing the US economy and the euro area in the last 25 years: (i) market work is much higher in the USA, (ii) the higher employment rate characterizing the USA relative to the euro area is mainly due to higher US employment in the services sector, (iii) labor tax rates are higher in the euro area, and (iv) the USA has a structural trade deficit, while the euro area as a whole runs persistent trade surpluses (and the USA has a persistent bilateral trade deficit with the euro area). The links between the former three facts have been recently analyzed in a few papers (Davis and Henrekson, 2004; Olovsson, 2004; Rogerson, 2005), while the links connecting the former three facts to the latter have not yet been recognized and modeled. The aim of this paper is exactly to provide an original two-country growth model that may help at shedding light on the possible relations linking these four facts.

* Manuscript received 1.10.06; final version received 25.9.09.

$\uparrow$ The authors thank the participants in the seminars given at the Department of Economics, Business and Statistics, University of Milan (Milan, June 2008) and at the Jerusalem Summer School in Economic Growth, Minerva Center for Economic Growth, Hebrew University of Jerusalem (Jerusalem, July 2008) for their helpful suggestions and comments. 
The set-up developed in this paper extends the dynamic general equilibrium models that incorporate home production (Benhabib et al., 1991; McGratten et al., 1997; Parente et al., 2000) along two dimensions, namely by distinguishing two market sectors and by integrating two similar economies that differ only with respect to tax rates (labor income taxes and possibly capital income taxes). The distinction between a market sector producing services that can be produced also in the non-market sector of the economy and a market sector producing goods that have no home-produced substitutes coincides in the model with the distinction between the sector producing internationally tradable goods and the sector producing non-tradables. Following the recent contributions analyzing the growth effect of increasing employment shares in the services (Echevarria, 1997; Kongsamut et al., 2001; Ngai and Pissarides, 2007; Bonatti and Felice, 2008), we assume that the market sector producing goods (i.e. the tradable sector) is subject to technological spillovers determining improvements in total factor productivity (it is a technologically 'progressive' industry), while the market sector producing services (i.e. the non-tradable sector) is not subject to technological spillovers (it is a 'stagnant' industry). ${ }^{1}$ However, in the model presented here, the stagnant industry uses an input (capital) that is produced by the progressive industry, thus benefiting indirectly by the possible improvements in total factor productivity achieved in the latter.

This set-up is also consistent with the literature incorporating nontradable goods in models of international trade; ${ }^{2}$ in particular, the distinction between a 'stagnant' non-tradable market service and a 'progressive' tradable good is at the basis of the well-known Harrod-Balassa-Samuelson effect. ${ }^{3}$ In this way, we show how differentials in labor tax rates across countries, which determine differences in the allocation of households' time between market activities and home activities, influence also the mix of tradable and nontradable goods that characterizes the market output of each country, thus affecting their bilateral trade balance.

The greater time spent in market work by Americans relative to Europeans is probably the most significant measure of the different performance of the labor market on the two sides of the Atlantic. Indeed, in 2004 the

${ }^{1}$ The 'progressive' sector can be identified with the manufacturing sector, with the possible inclusion of some service branches (transport, communications, financial services), which have experienced radical changes in their production processes because of the massive introduction of information and communication technologies. One can include in the 'stagnant' sector the remaining branches of services. A distinction along similar lines was proposed (but at the early stage of the information and communication technology revolution) by Baumol (1967) and Baumol et al. (1985).

${ }^{2}$ For an exhaustive presentation of a theoretical framework suited to study the role of nontradables in international trade, see Obstfeld and Rogoff (1996, Chapter 4).

${ }^{3}$ The Harrod-Balassa-Samuelson effect is the tendency for countries with higher productivity in tradables relative to non-tradables to have higher price levels (this tendency was originally noticed by David Ricardo). For a recent empirical assessment of the Harrod-BalassaSamuelson effect, see Alcalà and Ciccone (2004). 
TABLE 1

Country Differences in Market Work Time Per 15-64

Years Olds (Annual Hours Worked Per Person ${ }^{\mathrm{a}}$ )

\begin{tabular}{ccccc}
\hline Year & France & Germany $^{\mathrm{b}}$ & Italy & USA \\
\hline 1990 & 979 & 1004 & 871 & 1344 \\
2004 & 905 & 934 & 910 & 1299 \\
\hline
\end{tabular}

Source: Freeman and Schettkat (2005).

${ }^{\text {a}}$ Employed/population*annual hours worked per employee.

${ }^{\mathrm{b}}$ German figures on hours worked are for West Germany.

TABLE 2

Country Differences in Employment Rate

(EMPLOYED/Working-Age POPUlation ${ }^{\mathrm{a}}$ )

\begin{tabular}{ccccc}
\hline Year & France & Germany & Italy & USA \\
\hline 1998 & 0.594 & 0.641 & 0.508 & 0.738 \\
2004 & 0.628 & 0.655 & 0.574 & 0.712 \\
\hline
\end{tabular}

Source: OECD

${ }^{\mathrm{a} B e t w e e n} 15$ and 64 years old.

annual hours per person spent in market work were approximately one-third higher in the USA than in the three major countries of the euro area (see Table 1). However, this large difference in market work does not imply that total work time is much higher in the USA than in the euro area: the available evidence shows that Europeans tend to devote a larger fraction of their time to unpaid work at home, thus self-producing part of those services that Americans buy on the market (Davis and Henrekson, 2004; Olovsson, 2004; Freeman and Schettkat, 2005; Ragan, 2005; Rogerson, 2005; Burda et al., 2006). ${ }^{4}$ Consistently with this evidence, 'the relevant question is not why do Europeans work so little (. . ) but why do they choose to work so much at home' (Ragan, 2005, p. 4).

This tendency is related to the fact that the higher employment rate characterizing the USA relative to the euro area (see Table 2) is entirely due to the higher US employment in services. As the European Commission points out with reference to the late 1990s, 'The main difference in employment between the US and Europe is not in agriculture or manufacturing, where employment rates are broadly similar, but in services, where the

${ }^{4}$ Freeman and Schettkat (2005) emphasize that data from the Multinational Time Use Study show that in the early 1990s total work (market work plus time spent in household production) was approximately the same for US and European adults, although the amount of market work was higher in the USA. According to Burda et al. (2006), international comparisons of time-use diaries suggest that total work in the USA currently exceeds that in Germany and Italy, although the time devoted to home production is higher in Germany and Italy than in the USA. 
overall gap in employment rates is 14\% points' (European Commission, 1999, p. 12). ${ }^{5}$

A common explanation linking the difference in market work between the USA and the euro area to the gap between European and US employment shares in services rests on the higher tax rates on labor income to which the European households are subject. ${ }^{6}$ Davis and Henrekson (2004), Olovsson (2004) and Rogerson (2005) report evidence showing that persistently high tax rates depress labor supply and twist the mix of market employment and production away from services for which there are close non-market substitutes (preparing meals, cleaning and laundry, child and elderly care, shopping, repairs and maintenance etc.). As a matter of fact, market sectors producing goods that cannot be home produced (e.g. manufacturing goods) do not appear sensitive to personal tax rates (see Davis and Henrekson, 2004).

An unexplored implication of the structural differences brought about by persistent differentials in labor tax rates concerns international trade. It is not surprising, indeed, that policies and institutions determining long-term differences across countries in the time devoted to market activities and in the composition of market output may also have systematic effects on their trade account. In particular, one should consider that in general those market services that have close non-market substitutes are not internationally tradable, while the opposite is typically true for those goods that are combined with labor to produce both market services and their home-produced substitutes. Moreover, the demand for these tradable goods is likely to be higher in a country with lower labor taxes, as a consequence of the fact that in such a country the market production of services is greater and the home production of services is more goods intense (and less labor intense) than in a country where labor is taxed more heavily. One can also argue that the higher demand

${ }^{5}$ In 1997, the share of the working-age population (15-64 years) employed in industry was the same in the USA and in the EU (17.7), while the share employed in services was 54.5 in the USA and 39.7 in the EU. On the recent evolution of the gap between European and US employment shares in the aggregate services sector see D'Agostino et al. (2006).

${ }^{6}$ According to Prescott (2004), differences in the marginal tax rate on labor income can explain almost entirely the difference in worked hours between French, Germans and Italians on one side and Americans on the other side. He estimates that the marginal labor income tax rates in the period 1993-96 were 0.59 in Germany and France, 0.64 in Italy and 0.40 in the USA. Critics point out that the increase in tax rates occurred in Continental Europe in the 1970 s and in the 1980s, while the decline in worked time continued also during the 1990s (see Alesina et al., 2005). Furthermore, the available micro evidence shows that the role of the difference in tax rates in generating the large differential in market work between the European countries and the USA cannot be inferred from the individual labor supply elasticities alone (see Davis and Henrekson, 2004; Alesina et al., 2005; Ragan, 2005). However, one should also consider that countries with higher tax rates tend to have more generous tax-funded public programs and government transfers that weaken labor supply incentives, although one may expect that market work increases when a larger share of public expenditures is devoted to the provision of services that are close substitutes for home-produced services such as child or elderly care (see Ragan, 2005). 
TABLE 3

Euro Area Trade Balance with the USA (Billions

OF ECU/EURO)

\begin{tabular}{lllll}
\hline 1996 & 1998 & 2000 & 2002 & 2004 \\
4.64 & 14.72 & 30.23 & 58.29 & 59.71 \\
\hline
\end{tabular}

Source: Eurostat.

for tradable goods characterizing a country with lower labor taxes is not matched by the presence of more favorable conditions for the production of these goods in such a country rather than in a country with higher labor taxes, since the additional labor supply existing in a country with lower labor taxes tends to be absorbed by the higher demand for labor coming from the market sector producing (internationally) non-tradable services. Therefore, one should expect that in a two-country economy - where countries differ only with respect to their tax rates - the country with lower labor taxes tends to exhibit a trade deficit.

The above conclusion, which can be derived from the two-country model presented here, is consistent with the persistent bilateral trade deficit that the USA has with the euro area (see Table 3). Although one must obviously allow for the other factors influencing the bilateral trade balance between the USA and the euro area, which include the trade relations that both have with the rest of the world, this conclusion captures the structural component of the US trade deficit due to the fact that the non-tradable services represent a larger share of market output in the USA than in most other advanced countries.?

The paper is organized as follows. Section 2 presents the model; Section 3 characterizes the equilibrium trajectories of the two-country economy when one country has a higher labor tax rate than the other; Section 4 concludes.

\section{The Model}

In the two-country economy under consideration, there are firms that operate in the market sector producing an internationally tradable good and firms that operate in the market sector producing an internationally non-tradable service. Moreover, there are households that may consume both the marketproduced service and a home-produced service, and that can decide on the allocation of their time between work and leisure. Finally, there are national governments that tax labor and capital for making transfers to the households. The two countries differ with respect to the tax rates imposed by their respective government. The tradable good is used as capital in both market

\footnotetext{
${ }^{7}$ Mann (2004) emphasizes that technological factors that make services more tradable internationally should result in an improvement of the US structural trade deficit.
} 
sectors and in the home production process. Capital is internationally mobile, while labor is internationally immobile. However, both factors can freely move across sectors. All markets are perfectly competitive. Time is discrete and the time horizon is infinite. There is no source of random disturbances and agents' expectations are rational (in the sense that they are consistent with the true processes followed by the relevant variables), thus implying perfect foresight. ${ }^{8}$

\subsection{Firms Producing the (Internationally) Non-tradable Good}

In each country $i$, where $i=\mathrm{us}$, eu, there is a large number (normalized to be one) of firms producing the consumer service. They are identical and in each period $t$ they produce the consumer service $N_{i t}$ according to the following technology:

$$
N_{i t}=K_{i \mathrm{~N} t}^{1-\beta} L_{i \mathrm{~N} t}^{\beta} \quad 0<\beta<1
$$

where $K_{i \mathrm{~N} t}$ and $L_{i \mathrm{~N} t}$ are, respectively, the capital stock and the labor input used in country $i$ to produce the (internationally) non-tradable market service $N_{i t}$. In each $t$, firms use labor and rent capital in order to maximize their profits $\pi_{i \mathrm{~N} t}$, which are given by

$$
\pi_{i \mathrm{~N} t}=N_{i t}-W_{i t} L_{i \mathrm{~N} t}-R_{i t} K_{i \mathrm{~N} t}
$$

where $W_{i t}$ and $R_{i t}$ are, respectively, the wage rate and the rental rate on capital in country $i$. Notice that $N_{i t}$ is the numéraire of country $i$ and its price is normalized to be one. It is also assumed that $N_{i t}$ is not storable and must be immediately consumed. ${ }^{9}$

Since capital is internationally mobile, the following non-arbitrage condition must hold in each $t$ :

$$
R_{i t}=E_{i t} R_{j t} \quad i \neq j
$$

where $E_{i t}$ is the $i$-numéraire price of the $j$ numéraire, namely the price in units of the non-tradable good produced in $i$ of one unit of the non-tradable good produced in $j$.

\footnotetext{
${ }^{8}$ As already stated in Section 1, the distinction between two main sectors (tradables and nontradables), the existence of a productivity gap between the two, and the assumption that labor is mobile across sectors but not across countries while capital is mobile across both sectors and countries are consistent with the standard trade model developed by Obstfeld and Rogoff (1996, Chapter 4). We extend this framework by introducing home production and a technological spillover in the tradable sector. The latter replaces the assumption of exogenous productivity differences between the two sectors and generates endogenous growth.

${ }^{9}$ Typically, consumer services are consumed while they are produced.
} 


\subsection{Firms Producing the (Internationally) Tradable Good}

In each country $i$, there is a large number (normalized to be one) of firms producing the (internationally) tradable good. They are identical and in each period $t$ they produce $T_{i t}$ according to the following technology:

$$
T_{i t}=A_{i t} K_{i \mathrm{~T} t}^{1-\alpha} L_{i \mathrm{~T} t}^{\alpha} \quad 0<\alpha<1
$$

where $K_{i \mathrm{~T} t}$ and $L_{i \mathrm{~T} t}$ are, respectively, the capital stock and the labor input used in country $i$ to produce the (internationally) tradable good $T_{i t}$, and $A_{i t}$ is a variable measuring the state of technology of the firms operating in the market sector of country $i$ which produces the (internationally) tradable good $T_{i t}$. It is assumed that $A_{i t}$ is a positive function of the capital installed in the sector of $i$ which produces $T_{i t}: A_{i t}=K_{i \mathrm{~T} t}^{\alpha} \cdot{ }^{10}$ This assumption combines the idea that learning-by-doing works through each firm's capital investment and the idea that knowledge and productivity gains spill over instantly across all firms (see Barro and Xavier Sala-i-Martin, 1995). Therefore, in accordance with Frankel (1962), it is supposed that although $A_{i t}$ is endogenous to the economy, each firm takes it as given, since a single firm's decisions have only a negligible impact on the aggregate stock of capital of the tradable sector. ${ }^{11}$

In each period $t$, the firms producing $T_{i t}$ hire labor and rent capital in order to maximize their profits $\pi_{i \mathrm{~T} t}$, which are given by

$$
\pi_{i \mathrm{~T} t}=P_{i t} T_{i t}-W_{i t} L_{i \mathrm{~T} t}-R_{i t} K_{i \mathrm{~T} t}
$$

where $P_{i t}$ is the price of the tradable good (in units of $N_{i t}$ ) in country $i$.

The law of one price implies

$$
P_{i t}=E_{i t} P_{j t} \quad i \neq j
$$

\subsection{Households}

Households are infinitely lived. Their large number living in country $i$ is normalized to be one. The period utility function of the representative household of country $i$ is given by

$$
u_{i t}=\mu \ln \left(N_{i t}\right)+(1-\mu) \ln \left(H_{i t}\right)+\varphi \ln \left(L_{i \mathrm{~L} t}\right) \quad 0 \leq \mu \leq 1 \quad \varphi \geq 0
$$

where $N_{i t}$ is the amount of consumer service bought on the market, $H_{i t}$ is the amount of consumer service produced at home for self-consumption, and $L_{i \mathrm{~L} t}$

\footnotetext{
${ }^{10}$ Consistently with this formal set-up, one can interpret technological progress as labor augmenting.

${ }^{11}$ This amounts to saying that technological progress is endogenous to the economy, although it is an unintended by-product of firms' capital investment rather than the result of purposive R\&D efforts.
} 
is the time devoted to leisure. ${ }^{12}$ The consumer service $H_{i t}$ is produced at home according to the following technology:

$$
H_{i t}=K_{i \mathrm{H} t}^{1-\gamma} L_{i \mathrm{H} t}^{\gamma} \quad 0<\gamma<1
$$

where $K_{i \mathrm{H} t}$ and $L_{i \mathrm{H} t}$ are, respectively, the amount of capital and the time that households devote to home production. Note that consumer durables are interpreted as home capital: consistently with this interpretation, the (internationally) tradable sector produces only capital goods and the tradable good can be interpreted as a composite good representing those market-produced goods for which there is no home-produced substitute.

Given (3) and (6), the period budget constraint of the representative household can be written as

$$
\begin{array}{r}
P_{i t} K_{i t+1}+N_{i t} \leq\left(K_{i t}-K_{i \mathrm{H} t}\right)\left(1-\tau_{i \mathrm{~K}}\right) R_{i t}+\left(L-L_{i \mathrm{H} t}-L_{i \mathrm{~L} t}\right)\left(1-\tau_{i \mathrm{~L}}\right) W_{i t}+G_{i t} \\
0 \leq \tau_{i \mathrm{~K}}<1 \quad 0 \leq \tau_{i \mathrm{~L}}<1 \quad K_{i 0} \text { given }
\end{array}
$$

where $K_{i t}$ is the total amount of capital owned in $t$ by the representative household of country $i, L$ is the fixed amount of time endowed to each household, $G_{i t}$ are the fiscal transfers that each household receives in $t$ from its national government, $\tau_{i \mathrm{~K}}$ is the tax rate on capital income in country $i$ (all capital income - no matter whether generated in the home country or abroad - is subject in country $i$ to the same tax rate decided by the domestic authorities) and $\tau_{i \mathrm{~L}}$ is the tax rate on labor income in $i$. Note that the households' total time $L$ (market work plus time devoted to home production and to leisure) is assumed to be equal in the two countries. Again for simplicity full capital depreciation is assumed. ${ }^{13}$

In each $t$, the representative household must choose the sequences $\left\{K_{i n+1}\right\}_{n=t}^{\infty},\left\{N_{i n}\right\}_{n=t}^{\infty},\left\{K_{i \mathrm{H} n}\right\}_{n=t}^{\infty},\left\{L_{i \mathrm{H} n}\right\}_{n=t}^{\infty}$ and $\left\{L_{i \mathrm{~L} n}\right\}_{n=t}^{\infty}$ in order to maximize its discounted sequence of utility:

${ }^{12} \mathrm{We}$ assume that households choose between a market service and a home-produced substitute in order to capture the stylized fact mentioned in Section 1, i.e. that the differences in the use of time between the USA and EU are mainly (but not only, and for this reason we consider also leisure) due to a different allocation of working time between home and market activities. The results are robust to different specifications, however. Nonetheless, the specification here presented is more effective in reproducing the stylized facts on the use of time and on the dynamics of the main variables. In our specification the utility function is defined over $N, H$ and $L$. Good T (the internationally tradable good) enters the households' utility function only indirectly. Indeed, good $\mathrm{T}$ has to be considered as a composite intermediate good which gives utility only when combined with labor, either in the market $(\operatorname{good} \mathrm{N})$ or at home $(\operatorname{good} \mathrm{H})$. This assumption is consistent with the household production function approach (see Becker, 1965); our particular specification follows Pollak and Wachter (1975) and Benhabib et al. (1991).

${ }^{13}$ This assumption does not affect the main results of the paper, and it is reasonable considering that capital in this framework is a composite good that, besides entering the production of the tradable good, is combined with households' time in order to produce the home service and the non-market service (hence, it is also used as a consumer durable). 


$$
\sum_{n=t}^{\infty} \theta^{n-t} u_{i n} \quad \text { subject to (9) } \quad 0<\theta<1
$$

where $\theta$ is a time-preference parameter.

\subsection{Governments}

Each government balances its budget in each period:

$$
G_{i t}=\left(K_{i t}-K_{i \mathrm{H} t}\right) R_{i t} \tau_{i \mathrm{~K}}+\left(L-L_{i \mathrm{H} t}-L_{i \mathrm{~L} t}\right) W_{i t} \tau_{i \mathrm{~L}}
$$

\subsection{Markets Equilibrium}

Equilibrium in the market for the (internationally) non-tradable good produced in country $i$ requires

$$
N_{i t}^{\mathrm{s}}=N_{i t}^{\mathrm{d}}
$$

Equilibrium in the labor market of country $i$ requires

$$
L-L_{i \mathrm{H} t}-L_{i \mathrm{~L} t}=L_{i \mathrm{~T} t}+L_{i \mathrm{~N} t}
$$

Equilibrium in the world market for the (internationally) tradable good requires

$$
T_{\text {ust }}+T_{\text {eut }}=K_{\text {ust }+1}+K_{\text {eut } t+1}
$$

Equilibrium in the world market for capital requires

$$
K_{\text {us } t}-K_{\text {usH } t}+K_{\text {eut }}-K_{\text {euH } t}=K_{\text {usT } t}+K_{\text {usN } t}+K_{\text {euT } t}+K_{\text {euN } t}
$$

It is worth noting that in an open economy framework $K_{i t}$ may differ from $K_{i \mathrm{H} t}+K_{i \mathrm{~T} t}+K_{i \mathrm{~N} t}: K_{i t}$ is the capital owned by the residents of country $i$ which can be invested in the home sector of country $i$ and in the tradable and non-tradable sectors of country $i$ or $j, K_{i \mathrm{H} t}$ is the capital owned by the residents of country $i$ and used in their own home production, while $K_{i \mathrm{~T} t}$ and $K_{i \mathrm{~N} t}$ are the capital invested, respectively, in the tradable sector and in the non-tradable market sector of country $i$ which can be owned by the residents of both countries.

\section{Characterization of an Equilibrium Path}

Given (3), (6), (12), (13) and the agents' optimality conditions (A1)-(A7) (see the Appendix), the following equations must hold along an equilibrium path:

$$
\begin{aligned}
L_{i \mathrm{~T} t} & =L_{j \mathrm{~T} t} \quad i \neq j \\
L_{i \mathrm{H} t} & =\frac{(1-\mu) \gamma\left(L-L_{i \mathrm{~T} t}\right)}{(1-\mu) \gamma+\beta \mu\left(1-\tau_{i \mathrm{~L}}\right)+\varphi}
\end{aligned}
$$




$$
\begin{aligned}
& L_{i \mathrm{~N} t}=\frac{\beta \mu\left(1-\tau_{i \mathrm{~L}}\right)\left(L-L_{i \mathrm{~T} t}\right)}{(1-\mu) \gamma+\beta \mu\left(1-\tau_{i \mathrm{~L}}\right)+\varphi} \\
& L_{i \mathrm{~L} t}=\frac{\varphi\left(L-L_{i \mathrm{~T} t}\right)}{(1-\mu) \gamma+\beta \mu\left(1-\tau_{i \mathrm{~L}}\right)+\varphi} \\
& K_{i \mathrm{~N} t}=\frac{K_{i \mathrm{H} t}(1-\beta) \mu\left(1-\tau_{i \mathrm{~K}}\right)}{(1-\mu)(1-\gamma)} \\
& K_{i \mathrm{~T} t}=\frac{\left.K_{i \mathrm{H} t} L_{i \mathrm{~T} t} t(1-\mu) \gamma+\beta \mu\left(1-\tau_{i \mathrm{~L}}\right)+\varphi\right](1-\alpha)\left(1-\tau_{i \mathrm{~K}}\right)}{\alpha(1-\mu)(1-\gamma)\left(1-\tau_{i \mathrm{~L}}\right)\left(L-L_{i \mathrm{~T} t}\right)} \\
& E_{i t}=\left(\frac{L_{i \mathrm{~N} t} K_{j \mathrm{~N} t}}{L_{j \mathrm{~N} t} K_{i \mathrm{~N} t}}\right)^{\beta} i \neq j \\
& W_{i t}=\beta\left(\frac{\left.K_{i \mathrm{~N} t}\right)^{1-\beta}}{L_{i \mathrm{~N} t}}\right. \\
& R_{i t}=(1-\beta)\left(\frac{L_{i \mathrm{~N} t}}{K_{i \mathrm{~N} t}}\right)^{\beta} \\
& \rho_{i \mathrm{H} t}=\theta(1-\alpha)\left(1-\tau_{i \mathrm{~K}}\right) L_{i \mathrm{~T} t}^{\alpha}-1 \\
& P_{i t}=\frac{1-\beta}{(1-\alpha) L_{i \mathrm{~T} t}^{\alpha}}\left(\frac{L_{i \mathrm{~N} t}}{K_{i \mathrm{~N} t}}\right)^{\beta} \\
& \underbrace{}_{i \mathrm{H} t+1}-K_{i \mathrm{H} t} \\
& K_{i \mathrm{H} t}
\end{aligned}
$$

Note in (16) that the fraction of the households' time devoted to the production of the (internationally) tradable good is the same in the two countries at each point in time. This is due to the law of one price operating in the world market for the tradable good and to the equalization of returns in the world capital market, combined with the fact that labor is mobile across sectors but not across countries. ${ }^{14}$ Depending on taxation, what is different is the share of time devoted to $L_{i \mathrm{~L} t}, L_{i \mathrm{H} t}$ and $L_{i \mathrm{~N} t}$. In particular, the additional labor supply existing in a country with lower labor taxes tends to be absorbed by the higher demand for labor coming from the market sector producing (internationally) non-tradable services.

\footnotetext{
${ }^{14}$ Notice that the condition (16) does not hold in general under autarchy: in that case, different tax rates on labor in the two countries imply that they will exhibit different time shares in all sectors, together with different relative prices and average factor returns. Condition (16) does not hold in general also in a model with the same set-up but without spillovers in the production of the tradable good: in that case, the law of one price- together with capital mobility across sectors and countries and labor mobility across sectors, but not across countries - implies that the capital-labor ratio in the non-tradable sector of the two economies is the same at each point in time, and different tax rates on labor income do not determine differences in relative prices between the two countries $\left(E_{i t}=E_{j t}=1, P_{i t}=P_{j t}\right.$, $W_{i t}=W_{j t}, R_{i t}=R_{j t}$ for all $t$ ).
} 
Given (16), one can easily check in (17), (18) and (19) that the country with the higher tax rate on labor income devotes a larger share of the households' time to both home production and leisure and a smaller share of the households' time to the production of the market service, thus allocating less time to market activities.

Moreover, one can see by inspecting (20) and (21) that - other things being equal - the ratio between the capital installed in the tradable sector $\left(K_{i \mathrm{~T} t}\right)$ and the total capital installed in the country $\left(K_{i \mathrm{~T} t}+K_{i \mathrm{~N} t}+K_{i \mathrm{H} t}\right)$ is higher when labor income is taxed more heavily. It should be also apparent by looking at (16) and (25) that $P_{i t}$ and $P_{j t}$ differ if - and only if - the two countries display different capital-labor ratios in the non-tradable market sector.

Finally (26) shows - together with (16), (20) and (21) - that the capital installed in the country taxing the capital income less heavily grows faster. Indeed, $\tau_{i \mathrm{~K}}$ influences not only the pace at which the households located in $i$ accumulate productive assets, but also the rate at which the capital installed in $i$ grows. This is because the demand for the nontradable good and the production of the home-produced good tend to increase together with the households' income. Thus, the capital used by the firms operating in the non-tradable sector and the durables used in home production grow faster in the country where $\tau_{\text {i }}$ is lower. The same is true for the capital used in the tradable sector, since the optimizing behavior of firms operating in the same country and thus facing the same costs of labor and capital links the rate of growth of the capital installed in the tradable sector to that of the capital installed in the non-tradable sector.

Using (4), (14), (15), (16)-(26) and (A9) (see the Appendix), one can derive the system of difference equations in $X_{\mathrm{H} t}, Z_{\mathrm{ust}}$ and $L_{\mathrm{usT} t}-$ where $X_{\mathrm{H} t} \equiv K_{\mathrm{euH} t} / K_{\mathrm{usH} t}$ and $Z_{i t} \equiv K_{i t} / K_{i \mathrm{H} t}$-which governs the equilibrium path of the world economy:

$$
\begin{aligned}
& X_{\mathrm{H} t+1}=X_{\mathrm{H} t} \frac{1-\tau_{\text {euK }}}{1-\tau_{\text {usK }}} \\
& Z_{\mathrm{us} t+1}=f\left(Z_{\mathrm{us} t}, \frac{L_{\mathrm{usT} t}}{L-L_{\mathrm{usT} t}}\right) \\
& \frac{L_{\mathrm{usT} t+1}}{L-L_{\mathrm{usT} t+1}}=g\left(X_{\mathrm{H} t}, \frac{L_{\mathrm{usT} t}}{L-L_{\mathrm{usT} t}}\right)
\end{aligned}
$$

where

$$
f(\cdot)=\frac{Z_{\mathrm{ust}}-1}{\theta\left(1-\tau_{\mathrm{usK}}\right)}-\frac{1}{\theta(1-\mu)(1-\gamma)}\left\{\mu(1-\beta)-\frac{L_{\mathrm{usT} t}\left[(1-\mu) \gamma+\beta \mu\left(1-\tau_{\mathrm{usL}}\right)+\varphi\right]}{\left(L-L_{\mathrm{usT} t}\right)\left(1-\tau_{\mathrm{usL}}\right)}\right\}
$$

and 


$$
\begin{aligned}
& g(\cdot)=\frac{L_{\mathrm{usT} t}\left\{\begin{array}{c}
\left(1-\tau_{\mathrm{usK}}\right)\left[\frac{(1-\mu) \gamma+\varphi}{1-\tau_{\mathrm{usL}}}+\beta \mu\right] \\
+X_{\mathrm{H} t}\left(1-\tau_{\mathrm{euK}}\right)\left[\frac{(1-\mu) \gamma+\varphi}{1-\tau_{\mathrm{euL}}}+\beta \mu\right]
\end{array}\right\}}{\left(L-L_{\mathrm{usT} t}\right)(1-\alpha) \theta\left\{\begin{array}{c}
\left(1-\tau_{\mathrm{usK}}\right)^{2}\left[\frac{(1-\mu) \gamma+\varphi}{1-\tau_{\mathrm{usL}}}+\beta \mu\right] \\
+X_{\mathrm{H} t}\left(1-\tau_{\mathrm{euK}}\right)^{2}\left[\frac{(1-\mu) \gamma+\varphi}{1-\tau_{\mathrm{euL}}}+\beta \mu\right]
\end{array}\right\}} \\
& -\frac{\alpha(1-\mu)(1-\gamma)\left\{\begin{array}{c}
\frac{X_{\mathrm{H} t}\left(1-\tau_{\mathrm{euK}}\right)^{2}(1-\beta) \mu}{(1-\mu)(1-\gamma)}+X_{\mathrm{H} t}\left(1-\tau_{\mathrm{euK}}\right) \\
+\frac{\left(1-\tau_{\mathrm{usK}}\right)^{2}(1-\beta) \mu}{(1-\mu)(1-\gamma)}+\left(1-\tau_{\mathrm{usK}}\right)
\end{array}\right\}}{\left.(1-\alpha)\left\{\begin{array}{c}
\left(1-\tau_{\mathrm{usK}}\right)^{2}\left[\frac{(1-\mu) \gamma+\varphi}{1-\tau_{\mathrm{usL}}}+\beta \mu\right] \\
+X_{\mathrm{H} t}\left(1-\tau_{\mathrm{euK}}\right)^{2}\left[\frac{(1-\mu) \gamma+\varphi}{1-\tau_{\mathrm{euL}}}+\beta \mu\right.
\end{array}\right]\right\}}
\end{aligned}
$$

The equilibrium path governed by (27)-(29) is studied under the assumption that $\tau_{\mathrm{euK}} \geq \tau_{\mathrm{usK}}$ and $\tau_{\mathrm{euL}}>\tau_{\mathrm{usL}}$.

\subsection{Case in which $\tau_{\mathrm{euK}}=\tau_{\mathrm{usK}}$ and $\tau_{\mathrm{euL}}>\tau_{\mathrm{usL}}$}

In this case, the following proposition holds.

Proposition 1: If $\tau_{\mathrm{euK}}=\tau_{\mathrm{usK}}$ and $\tau_{\mathrm{euL}}>\tau_{\mathrm{usL}}$, (i) the equilibrium path of the world economy is unique, (ii) the amount of tradable goods used in the US economy exceeds the US production of tradable goods and the US economy runs a trade deficit for all $t$, (iii) the US GDP and the EU GDP grow at the same rate, and (iv) this equilibrium rate of growth is increasing with the fraction of the world stock of capital that is initially owned by the US households.

Proof: See the Appendix.

The unique equilibrium path of the two-country economy is such that $X_{\mathrm{H} t}=X_{\mathrm{H}}^{*}, Z_{\mathrm{us} t}=Z_{\mathrm{us}}^{*}$ and $L_{\mathrm{usT} t}=L_{\mathrm{usT}}^{*}$ for all $t$, where $*$ denotes the equilibrium value of a variable when the markets are internationally integrated and $\tau_{\text {euK }}=\tau_{\text {usK. }}$. Along the equilibrium path, the fraction of the world stock of capital that is owned by the US households does not change, and the initial distribution of the world stock of capital between the US and the EU 
households has a permanent influence on the equilibrium values of $X_{\mathrm{H} t}, Z_{\mathrm{us} t}$ and $L_{\text {usT } t}$.

In the country where labor is taxed more heavily, namely in the EU, households devote less time to market activities and tend to reduce their demand for the market service $N_{\text {eut }}$, thus depressing the domestic production of the non-tradable good. In contrast, the EU production of the tradable good is not depressed, since the EU exports a portion of its tradable output to the USA, where the demand for market goods tends to be more buoyant. This is reflected by the fact that in equilibrium the tradable good is relatively less expensive in the $\mathrm{EU}\left(P_{\mathrm{ust}}>P_{\text {eut }}\right)$, where the tax rate on labor is higher. ${ }^{15}$ Hence the US trade account, $\mathrm{TA}_{\text {ust }}=P_{\text {ust }}\left(T_{\text {ust }}-K_{\text {ust }+1}\right)$, is permanently negative ( $T_{\text {us } t}<K_{\text {ust }+1}$ for all $\left.t\right) .{ }^{16}$ Note also that the sustainability of the permanent trade deficit of the lower-tax-rate country is guaranteed by its positive income account, namely by the net flow of payments that the lower-tax-rate country receives from abroad thanks to the excess of the capital owned by its households over the capital invested within the country $\left(K_{\mathrm{ust}}>K_{\mathrm{usT} t}+K_{\mathrm{usN} t}+K_{\mathrm{usH} t}\right){ }^{17}$

It is worth noting that in the present framework trade is induced only by the differences in tax rates (on labor and possibly on capital): if $\tau_{\text {euK }}$ $=\tau_{\text {usK }}$ and $\tau_{\text {euL }}=\tau_{\text {usL }}$ there is no trade, since the two economies are perfectly identical.

Moreover, one should observe that the difference in the labor tax rate does not determine a differential in the growth rate of the two economies. By exporting the tradable good to the lower-tax-rate country, the higher-tax-rate country can enlarge the size of its technologically advanced sector, thus boosting its growth rate.

Finally, the fact that the world demand for the tradable good is higher if the weight of the US households in the world demand for the tradable good is greater explains why a distribution of the world stock of wealth more favorable to the US households raises the equilibrium rate of growth of the world economy, since the pace of technological progress increases in each country with the rate at which its tradable sector expands.

\subsection{Case in which $\tau_{\mathrm{euK}}>\tau_{\mathrm{usK}}$ and $\tau_{\mathrm{euL}}>\tau_{\mathrm{usL}}$}

In this case, the following proposition holds.

\footnotetext{
${ }^{15}$ Along the equilibrium path, $X_{\mathrm{H} t}$ is constant and equal to the initial rate $X_{\mathrm{H} 0}$, which is larger than one for all the relevant values of the parameters, thus implying (see (20)) that $K_{\mathrm{euN} t} / K_{\mathrm{usN} t}=$ $K_{\text {euN } 0} / K_{\text {usN } 0}>1$. Moreover, along an equilibrium path, $L_{\text {usN } t}>L_{\text {euN } t}$, which-together with $K_{\text {euN } t}>K_{\text {usN } t}$ - entails $P_{\text {ust }}>P_{\text {eut }}$.

${ }^{16}$ Along the equilibrium path, the US trade deficit-GDP ratio is equal to a (positive) constant.

${ }^{17}$ From the households' budget constraint and the firms' zero-profit condition one can derive $\mathrm{TA}_{i t}=-\mathrm{IA}_{i t}$, where $\mathrm{IA}_{i t} \equiv R_{i t}\left(K_{i t}-K_{i \mathrm{H} t}-K_{i \mathrm{~N} t}-K_{i \mathrm{~T} t}\right)$ is the income account of country $i$.
} 


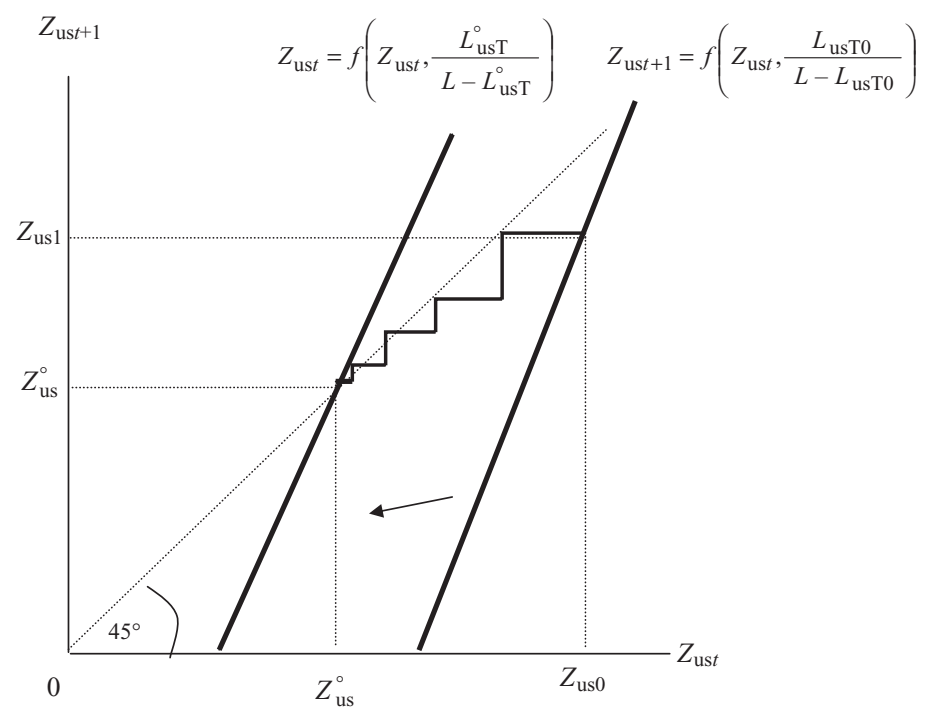

FIG. 1 Phase Line of Equation (28)

Proposition 2: If $\tau_{\mathrm{euK}}>\tau_{\mathrm{usK}}$ and $\tau_{\mathrm{euL}}>\tau_{\mathrm{usL}}$, (i) the equilibrium path of the world economy is unique, (ii) the amount of tradable goods used in the US economy exceeds the US production of tradable goods and the US economy runs a trade deficit for all $t<\infty$, and (iii) in the long term the US GDP grows at a higher rate than the EU GDP.

Proof: See the Appendix.

The unique equilibrium path of the two-country economy is such that as $t \rightarrow \infty X_{\mathrm{H} t} \rightarrow X_{\mathrm{H}}^{\circ}, Z_{\mathrm{us} t} \rightarrow Z_{\mathrm{us}}^{\circ}$ and $L_{\text {usT } t} \rightarrow L_{\text {usT }}^{\circ}$, where ${ }^{\circ}$ denotes the longterm equilibrium value of a variable when the markets are internationally integrated and $\tau_{\text {euK }}>\tau_{\text {usk. }}$. Along this path, $X_{\mathrm{H} t}, Z_{\text {ust } t}$ and $L_{\text {usT } t}$ converge monotonically to their respective long-term values (see Figs 1 and 2), and the buoyant demand for the tradable good coming from the low-tax country is partially met by the production of the high-tax country. This is at the origin of the persistent trade deficit of the low-tax country, which vanishes only as $t \rightarrow \infty$, since asymptotically the fraction of the US demand for the tradable good that is met by the EU production becomes negligible because of the permanent growth differential between the two countries. Indeed, the country taxing the capital income less heavily tends to grow faster because the capital installed by its firms - and consequently the total factor productivity of its tradable sector-grows permanently at a higher rate. 


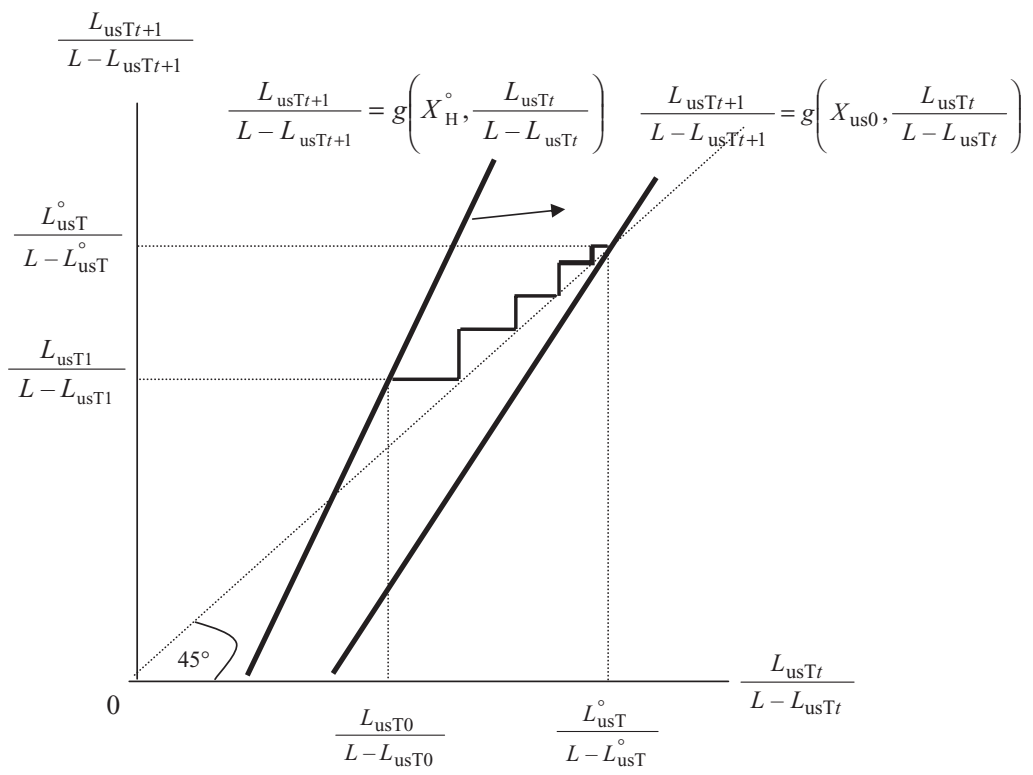

FIG. 2 Phase Line of Equation (29)

The fact that the total factor productivity tends to grow faster in the tradable sector of the lower-tax-rate country rather than in the tradable sector of the higher-tax-rate country explains why along a balanced growth path the price of tradables in terms of non-tradables declines at a higher rate in the USA than in the EU. The tradable good tends to become relatively more expensive in the higher-tax-rate country, and the EU trade surplus - due to the greater relative competitiveness of its tradable sector-vanishes asymptotically. ${ }^{18}$

\subsection{International Market Integration versus Autarky}

Proposition 3: If $\tau_{\text {euK }} \geq \tau_{\text {usK }}$ and $\tau_{\text {euL }}>\tau_{\text {usL }}$, in the long term the EU economy devotes more time to market activities (even if it devotes less time to the production of the non-tradable good) and has a higher rate of GDP growth under international market integration than under autarky.

Proof: See the Appendix.

Under free trade, the production of the tradable good is boosted in the high-tax country by the demand of the low-tax country. This explains why

${ }^{18}$ This asymptotic result is consistent with the Harrod-Balassa-Samuelson effect mentioned in Section 1. 
the households located in the EU devote a larger share of their time to the production of the tradable good under free trade than under autarky (when the external stimulus to the production of tradables is absent). Considering that the tradable sector is subject to technological spillovers, this explains also why the EU economy exhibits a higher long-term rate of growth under free trade than under autarky (displaying higher $K_{\text {euTt }} / K_{\text {euN } t}$ and $K_{\text {euT } t} / K_{\text {euH } t}$ ratios). The opposite is true for the USA, which devotes more resources to the tradable sector and displays a higher long-term rate of growth under autarky than under free trade.

\subsection{Consequences of a Cut in the EU Tax Rate on Capital Income for the US Growth Performance}

Suppose that initially $\tau_{\text {euK }}>\tau_{\text {usK }}$ and $\tau_{\text {euL }}>\tau_{\text {usL }}$ and that then the EU authorities decide a tax cut aimed at making the tax rates on capital income equal across countries. This cut worsens the long-term growth performance of the US economy.

Proposition 4: If $\tau_{\mathrm{euK}}>\tau_{\mathrm{usK}}$ and $\tau_{\mathrm{euL}}>\tau_{\mathrm{usL}}$, a cut in the EU tax rate on capital income from $\tau_{\text {euK }}$ to $\tau_{\text {euK }}^{\prime}=\tau_{\text {usK }}$ determines a decrease in the long-term rate of growth of the US GDP.

\section{Proof: See the Appendix.}

When $\tau_{\text {euK }}>\tau_{\text {usK }}$ and $\tau_{\text {euL }}>\tau_{\text {usL }}$, there is a permanent growth differential in favor of the US economy and the US demand for the tradable good is increasingly met by the domestic production. This does not occur when $\tau_{\text {euK }}^{\prime}=\tau_{\text {usK }}$ and $\tau_{\text {euL }}>\tau_{\text {usL }}$ : even in the long run-under these circumstances - a significant portion of the US demand for the tradable good is met by the EU production. Therefore, the US tradable sector remains smaller and attracts relatively less labor and capital when the tax rates on capital income are equalized. As a result, the long-term rate of growth of the US economy is lower when $\tau_{\mathrm{euK}}^{\prime}=\tau_{\mathrm{usK}}$ and $\tau_{\mathrm{euL}}>\tau_{\mathrm{usL}}$, since the technological progress feeding the growth process takes place in the tradable sector.

\section{Conclusion}

The two-country model developed in this paper intends to study economies that differ only with respect to tax rates (labor income taxes and possibly capital income taxes). The analysis is conducted under the simplifying assumptions that the (internationally) tradable goods coincide with the market goods which have no home-produced substitutes and that technological spillovers generating improvements in total factor productivity can 
occur only in the tradable sector. In this set-up, it is shown that market work is higher in the country with the lower tax rate on labor income, that the higher market work characterizing the country with the lower tax rate on labor income is entirely due to higher employment in the sector producing services which have close home-produced substitutes, and that the country with the lower tax rate on labor income has a persistent trade deficit.

This set-up has also implications for long-run growth. Considering that the tradable sector is subject to advances in total factor productivity, the fact that under free trade the production of the tradable good is boosted in the high-tax country by the demand coming from the low-tax country explains why the high-tax economy exhibits a higher long-term rate of growth under free trade than under autarky. The opposite is true for the low-tax country, which devotes more resources to the tradable sector and displays a higher long-term rate of growth under autarky than under free trade.

The two-country model contained in this paper has been developed with the main aim of shedding light on the possible relations linking three important and structural differences between the US economy and the euro area (i.e. higher market work and employment rate in the USA, higher tax rates on labor in the euro area) with the persistent trade deficit of the US economy with the euro area. Nonetheless, the model may also be suitable to investigate the differences across European countries and represent a useful framework for empirical research.

Future theoretical research can extend this framework by adding the public supply of a close substitute of the service good produced in the marketplace and at home. In this way, one might compare the results emerging in this extended set-up with those obtained in the benchmark framework in which households receive only fiscal transfer from their national government. This extended analysis should help us to understand how different policies and alternative institutional systems interact with technological progress in shaping the allocation of time in advanced economies.

\section{APPENDIX}

\section{Agents' Optimality Conditions}

The firms producing the non-tradable good in country $i$ satisfy the following optimality conditions:

$$
\begin{aligned}
& \beta\left(\frac{K_{i \mathbb{N} t}}{L_{i \mathbb{N}}}\right)^{1-\beta}=W_{i t} \\
& (1-\beta)\left(\frac{K_{i \mathbb{N} t}}{L_{i \mathbb{N} t}}\right)^{-\beta}=R_{i t}
\end{aligned}
$$


Similarly, the firms producing the tradable good in country $i$ satisfy the following optimality conditions:

$$
\begin{aligned}
& \frac{P_{i t} \alpha K_{i \mathrm{~T} t}}{L_{i \mathrm{~T} t}^{1-\alpha}}=W_{i t} \\
& P_{i t}(1-\alpha) L_{i \mathrm{~T} t}^{\alpha}=R_{i t}
\end{aligned}
$$

One can solve the households' problem by maximizing

$$
\begin{aligned}
& \sum_{n=t}^{\infty} \theta^{n-t}\left\{\mu \ln \left(N_{i n}\right)+(1-\mu) \ln \left(K_{i \mathrm{H} n}^{1-\gamma} L_{i \mathrm{H} n}^{\gamma}\right)+\varphi \ln \left(L_{i \mathrm{~L} n}\right)\right. \\
& \left.\quad-\lambda_{i n}\left[K_{i n+1} P_{i n}+N_{i n}-\left(K_{i n}-K_{i \mathrm{H} n}\right) R_{i n}\left(1-\tau_{i \mathrm{~K}}\right)-\left(L-L_{i \mathrm{H} n}-L_{i \mathrm{~L} n}\right) W_{i n}\left(1-\tau_{i \mathrm{~L}}\right)-G_{i n}\right]\right\}
\end{aligned}
$$

with respect to $N_{i t}, K_{i \mathrm{H} t}, L_{i \mathrm{H} t}, L_{i \mathrm{~L} t}, K_{i t+1}$ and the Lagrange multiplier $\lambda_{i t}$, and then by eliminating $\lambda_{i t}$, thus obtaining

$$
\begin{aligned}
K_{i \mathrm{~N} t} & =\frac{K_{i \mathrm{H} t}(1-\beta) \mu\left(1-\tau_{i \mathrm{~K}}\right)}{(1-\mu)(1-\gamma)} \\
L_{i \mathrm{~N} t} & =\frac{L_{i \mathrm{H} t} \beta \mu\left(1-\tau_{i \mathrm{~L}}\right)}{(1-\mu) \gamma} \\
L_{i \mathrm{~L} t} & =\frac{L_{i \mathrm{~N} t} \varphi}{\beta \mu\left(1-\tau_{i \mathrm{~L}}\right)} \\
\rho_{i \mathrm{H} t} & =\theta(1-\alpha)\left(1-\tau_{i \mathrm{~K}}\right) L_{i \mathrm{~T} t}^{\alpha}-1 \quad \rho_{i \mathrm{H} t} \equiv \frac{K_{i \mathrm{H} t+1}-K_{i \mathrm{H} t}}{K_{i \mathrm{H} t}} \\
\theta\left(1-\tau_{i \mathrm{~K}}\right) Z_{i t+1} & =Z_{i t}-\frac{1-\tau_{i \mathrm{~K}}}{(1-\mu)(1-\gamma)}\left\{\mu(1-\beta)-\frac{L_{i \mathrm{~T} t}\left[(1-\mu) \gamma+\beta \mu\left(1-\tau_{i \mathrm{~L}}\right)+\varphi\right]}{\left(1-\tau_{i \mathrm{~L}}\right)\left(L-L_{i \mathrm{~T} t}\right)}\right\}-1 \\
Z_{i t} \equiv \frac{K_{i t}}{K_{i \mathrm{H} t}} &
\end{aligned}
$$

Therefore, along an optimal path a household located in $i$ must satisfy (A5)-(A9) and the transversality condition

$$
\lim _{t \rightarrow \infty} \theta^{t} Z_{i t} \mu\left[\frac{K_{i \mathrm{H} t}(1-\beta) \gamma\left(1-\tau_{i \mathrm{~K}}\right)}{L_{i \mathrm{H} t} \beta(1-\gamma)\left(1-\tau_{i \mathrm{~L}}\right)}\right]^{\beta}=0
$$

\section{Proof of Proposition 1}

(i) If $\tau_{\mathrm{euK}}=\tau_{\mathrm{usK}}$, equation (27) entails $X_{\mathrm{H} t}=X_{\mathrm{H} 0}$ for all $t$. Given $X_{\mathrm{H} t}=X_{\mathrm{H} 0}$ and

$$
\frac{\partial g\left(X_{\mathrm{H} 0}, \frac{L_{\mathrm{usT} t}}{L-L_{\mathrm{usT} t}}\right)}{\partial \frac{L_{\mathrm{usT} t}}{L-L_{\mathrm{usT} t}}}>1 \quad \text { for all } t
$$


it turns out that the only path that satisfies (29) and does not violate boundary conditions must be such that

$$
\frac{L_{\mathrm{usT}}^{*}}{L-L_{\mathrm{usT}}^{*}}=g\left(X_{\mathrm{H} 0}, \frac{L_{\mathrm{usT}}^{*}}{L-L_{\mathrm{usT}}^{*}}\right) \quad \text { for all } t
$$

Given $L_{\mathrm{usT} t}=L_{\mathrm{usT}}^{*}$ and

$$
\frac{\partial f\left(Z_{\mathrm{us} t}, \frac{L_{\mathrm{usT}}^{*}}{L-L_{\mathrm{usT}}^{*}}\right)}{\partial Z_{\mathrm{us} t}}>1 \quad \text { for all } t
$$

it turns out that the only path that satisfies (28) and does not violate transversality or boundary conditions must be such that

$$
Z_{\mathrm{us}}^{*}=f\left(Z_{\mathrm{usT}}^{*}, \frac{L_{\mathrm{usT}}^{*}}{L-L_{\mathrm{usT}}^{*}}\right) \quad \text { for all } t
$$

Given (16), (20), (21), $L_{\mathrm{usT} t}=L_{\mathrm{usT}}^{*}$ and $Z_{\mathrm{us} t}=Z_{\text {us }}^{*}$ for all $t$, at $t=0$ one has

$$
\begin{aligned}
K_{\mathrm{us} 0}+K_{\mathrm{eu} 0}= & K_{\mathrm{usH} 0}\left\{1+\frac{(1-\beta) \mu\left(1-\tau_{\mathrm{usK}}\right)}{(1-\mu)(1-\gamma)}\right. \\
& \left.+\frac{L_{\mathrm{usT}}^{*}\left(1-\tau_{\mathrm{usK}}\right)(1-\alpha)}{\left(L-L_{\mathrm{usT}}^{*}\right)(1-\mu)(1-\gamma) \alpha}\left[\frac{(1-\mu) \gamma+\varphi}{1-\tau_{\mathrm{usL}}}+\beta \mu\right]\right\} \\
& +K_{\mathrm{usH} 0} X_{\mathrm{H} 0}\left\{1+\frac{(1-\beta) \mu\left(1-\tau_{\mathrm{euK}}\right)}{(1-\mu)(1-\gamma)}\right. \\
& \left.+\frac{L_{\mathrm{usT}}^{*}\left(1-\tau_{\mathrm{euK}}\right)(1-\alpha)}{\left(L-L_{\mathrm{usT}}^{*}\right)(1-\mu)(1-\gamma) \alpha}\left[\frac{(1-\mu) \gamma+\varphi}{1-\tau_{\mathrm{euL}}}+\beta \mu\right]\right\}
\end{aligned}
$$

which entails

$$
\begin{aligned}
Z_{\mathrm{us}}^{*}= & \frac{K_{\mathrm{us} 0}}{\left(K_{\mathrm{us} 0}+K_{\mathrm{eu} 0}\right)}\left\{1+\frac{(1-\beta) \mu\left(1-\tau_{\mathrm{usK}}\right)}{(1-\mu)(1-\gamma)}\right. \\
& \left.+\frac{L_{\mathrm{usT}}^{*}\left(1-\tau_{\mathrm{usK}}\right)(1-\alpha)}{\left(L-L_{\mathrm{usT}}^{*}\right)(1-\mu)(1-\gamma) \alpha}\left[\frac{(1-\mu) \gamma+\varphi}{1-\tau_{\mathrm{usL}}}+\beta \mu\right]\right\} \\
& +\frac{K_{\mathrm{us} 0} X_{\mathrm{H} 0}}{K_{\mathrm{us} 0}+K_{\mathrm{eu} 0}}\left\{1+\frac{(1-\beta) \mu\left(1-\tau_{\mathrm{euK}}\right)}{(1-\mu)(1-\gamma)}\right. \\
& \left.+\frac{L_{\mathrm{usT}}^{*}\left(1-\tau_{\mathrm{euK}}\right)(1-\alpha)}{\left(L-L_{\mathrm{usT}}^{*}\right)(1-\mu)(1-\gamma) \alpha}\left[\frac{(1-\mu) \gamma+\varphi}{1-\tau_{\mathrm{euL}}}+\beta \mu\right]\right\}
\end{aligned}
$$

where $K_{\text {us } 0}$ and $K_{\text {eu } 0}$ are given.

Having shown that $X_{\mathrm{H} t}=X_{\mathrm{H} 0}, L_{\mathrm{usT} t}=L_{\mathrm{usT}}^{*}$ and $Z_{\mathrm{us} t}=Z_{\mathrm{us}}^{*}$ for all $t$, one can prove the uniqueness of the equilibrium path of the world economy when $\tau_{\text {euK }}=\tau_{\text {usK }}$ by checking that the triple $\left(X_{\mathrm{H} 0}, Z_{\mathrm{us}}^{*}, L_{\mathrm{usT}}^{*}\right)$ which solves (A11)-(A13) is unique, where 


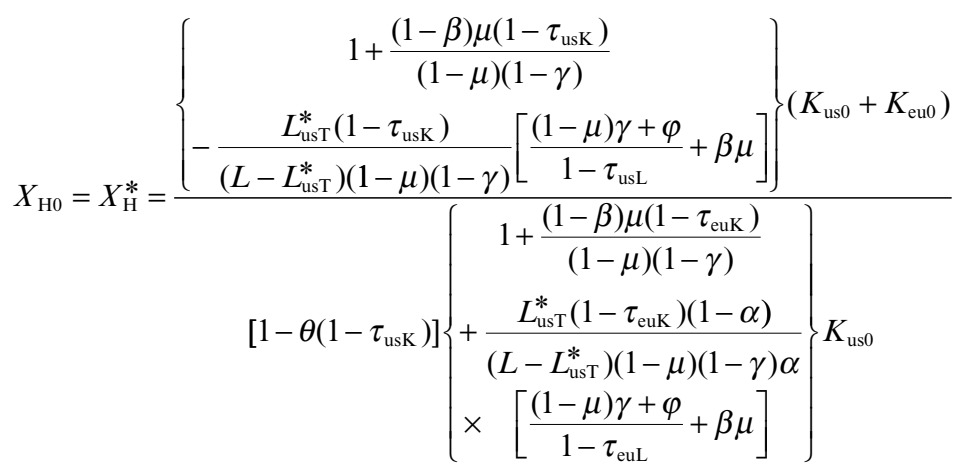

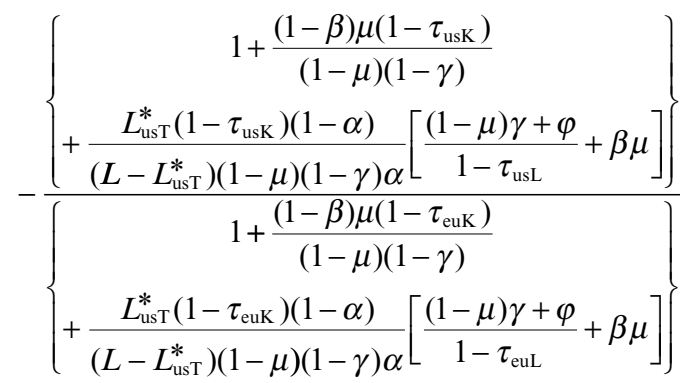

$$
\begin{aligned}
& Z_{\mathrm{us}}^{*}=\frac{\frac{1-\tau_{\mathrm{usK}}}{(1-\gamma)(1-\mu)}\left\{\mu(1-\beta)-\frac{L_{\mathrm{usT}}^{*}}{L-L_{\mathrm{usT}}^{*}}\left[\frac{\gamma(1-\mu)+\varphi}{1-\tau_{\mathrm{usL}}}+\beta \mu\right]\right\}+1}{1-\theta\left(1-\tau_{\mathrm{usK}}\right)} \\
& L_{\mathrm{usT}}^{*}=\frac{L\left[\frac{Q}{2 M}-\sqrt{\left(\frac{Q}{2 M}\right)^{2}-\frac{V}{M}}\right]}{1+\frac{Q}{2 M}-\sqrt{\left(\frac{Q}{2 M}\right)^{2}-\frac{V}{M}}} \\
& V \equiv \theta\left[1+\frac{(1-\beta) \mu\left(1-\tau_{\text {usK }}\right)}{(1-\mu)(1-\gamma)}\right]^{2} \\
& M \equiv \frac{1-\theta\left(1-\tau_{\mathrm{usK}}\right)(1-\alpha)}{\alpha(1-\mu)^{2}(1-\gamma)}\left[\frac{\gamma(1-\mu)+\varphi}{1-\tau_{\mathrm{euL}}}+\beta \mu\right]\left[\frac{\gamma(1-\mu)+\varphi}{1-\tau_{\mathrm{usL}}}+\beta \mu\right] \\
& Q \equiv\left[1+\frac{(1-\beta) \mu\left(1-\tau_{\text {usK }}\right)}{(1-\mu)(1-\gamma)}\right]\left\{\frac{\theta\left(1-\tau_{\text {usK }}\right)}{1-\mu}\left[\frac{\gamma(1-\mu)+\varphi}{1-\tau_{\text {usL }}}+\beta \mu\right]\right. \\
& \left.-\left[\frac{1}{1-\tau_{\mathrm{euL}}}-\frac{1}{1-\tau_{\mathrm{usL}}}\right] \frac{\gamma K_{\mathrm{us} 0}\left[1-\theta\left(1-\tau_{\mathrm{usK}}\right)\right]}{\alpha\left(K_{\mathrm{us} 0}+K_{\mathrm{eu} 0}\right)}\right\} \\
& +\frac{\left[1-\theta\left(1-\tau_{\mathrm{usK}}\right)(1-\alpha)\right]}{\alpha(1-\mu)}\left[1+\frac{(1-\beta) \mu\left(1-\tau_{\mathrm{usK}}\right)}{(1-\mu)(1-\gamma)}\right]\left[\frac{\gamma(1-\mu)+\varphi}{1-\tau_{\mathrm{euL}}}+\beta \mu\right] \\
& K_{\text {us } 0} \text { and } K_{\text {eu } 0} \text { given }
\end{aligned}
$$


(ii) The US trade account, $\mathrm{TA}_{\mathrm{us} t}$, is given by $\mathrm{TA}_{\mathrm{ust}}=P_{\mathrm{ust}}\left(T_{\mathrm{ust}}-K_{\mathrm{us} t+1}\right)$, which-using (4), (21), (25) and (26) — can be rewritten as

$$
\mathrm{TA}_{\mathrm{us} t}=\frac{(1-\gamma)(1-\mu) K_{\mathrm{usN} t}^{1-\beta} L_{\mathrm{usN} t}^{\beta}}{\mu}\left\{\frac{L_{\mathrm{usT} t}\left[(1-\mu) \gamma+\beta \mu\left(1-\tau_{\mathrm{usL}}\right)+\varphi\right]}{\left(L-L_{\mathrm{usT} t}\right)\left(1-\tau_{\mathrm{usL}}\right)(1-\mu)(1-\gamma) \alpha}-\theta Z_{\mathrm{us} t+1}\right\}
$$

By substituting $L_{\mathrm{usT}}^{*}$ for $L_{\mathrm{usT} t}$ and $Z_{\mathrm{us}}^{*}$ for $Z_{\mathrm{us} t+1}$ in (A17), one can verify that $\mathrm{TA}_{\mathrm{us} t}<0$ for all $t$.

(iii) The GDP of country $i, \mathrm{GDP}_{i t}$, is given by $\mathrm{GDP}_{i t}=N_{i t}+P_{i t} T_{i t}$, whose rate of growth is

$$
\rho_{i \mathrm{GDP} t}=\frac{N_{i t+1}+P_{i t+1} T_{i t+1}-\left(N_{i t}+P_{i t} T_{i t}\right)}{N_{i t}+P_{i t} T_{i t}} \quad \rho_{i \mathrm{GDP} t} \equiv \frac{\mathrm{GDP}_{i t+1}-\mathrm{GDP}_{i t}}{\mathrm{GDP}_{i t}}
$$

By using (1), (4), (16), (18), (20), (21), (25) and (26), one can check that $\rho_{\text {usGDP } t}^{*}=\rho_{\text {euGDP } t}^{*}$, where ${ }^{19}$

$$
\rho_{i \mathrm{GDP} t}^{*}=\rho_{i \mathrm{GDP}}^{*}=\left[\theta(1-\alpha)\left(1-\tau_{i \mathrm{~K}}\right)\left(L_{i \mathrm{~T}}^{*}\right)^{\alpha}\right]^{1-\beta}-1
$$

(iv) By using (A16) and (A18), one can check that

$$
\frac{\partial \rho_{i \mathrm{GDP} t}^{*}}{\partial \frac{K_{\mathrm{us} 0}}{K_{\mathrm{us} 0}+K_{\text {eu } 0}}}>0
$$

\section{Proof of Proposition 2}

(i) If $\tau_{\mathrm{euK}}>\tau_{\mathrm{usK}}$, one can verify that the triple $\left(X_{\mathrm{H}}^{\circ}, Z_{\mathrm{us}}^{\circ}, L_{\mathrm{usT}}^{\circ}\right)$ satisfying $X_{\mathrm{H} t+1}=X_{\mathrm{H} t}=X_{\mathrm{H}}^{\circ}$, $Z_{\mathrm{us} t+1}=Z_{\mathrm{us} t}=Z_{\mathrm{us}}^{\circ}$ and $L_{\mathrm{usT} t+1}=L_{\mathrm{usT} t}=L_{\mathrm{usT}}^{\circ}$ in equations (27)-(29) is unique, where

$$
X_{\mathrm{H}}^{\circ}=0
$$

$$
\begin{gathered}
Z_{\mathrm{us}}^{\circ}=\frac{\frac{1-\tau_{\mathrm{usK}}}{(1-\gamma)(1-\mu)}\left\{\mu(1-\beta)-\frac{L_{\mathrm{usT}}^{\circ}}{L-L_{\mathrm{usT}}^{\circ}}\left[\frac{\gamma(1-\mu)+\varphi}{1-\tau_{\mathrm{usL}}}+\beta \mu\right]\right\}+1}{1-\theta\left(1-\tau_{\mathrm{usK}}\right)} \\
L_{\mathrm{usT}}^{\circ}=\frac{L\left[\frac{\left(1-\tau_{\mathrm{usK}}\right)(1-\beta) \mu}{(1-\gamma)(1-\mu)}+1\right] \theta \alpha(1-\gamma)(1-\mu)\left(1-\tau_{\mathrm{usL}}\right)}{\left\{\begin{array}{l}
{\left[1-\theta(1-\alpha)\left(1-\tau_{\mathrm{usK}}\right)\right]\left[\gamma(1-\mu)+\beta \mu\left(1-\tau_{\mathrm{usL}}\right)+\varphi\right]} \\
+\left[\frac{\left(1-\tau_{\mathrm{usK}}\right)(1-\beta) \mu}{(1-\gamma)(1-\mu)}+1\right] \theta \alpha(1-\gamma)(1-\mu)\left(1-\tau_{\mathrm{usL}}\right)
\end{array}\right\}}
\end{gathered}
$$

A formal proof of the uniqueness of the equilibrium path in a neighborhood of $\left(X_{\mathrm{H}}^{\circ}, Z_{\mathrm{us}}^{\circ}, L_{\mathrm{usT}}^{\circ}\right)$ is provided by linearizing (27)-(29) around $\left(X_{\mathrm{H}}^{\circ}, Z_{\mathrm{us}}^{\circ}, L_{\mathrm{usT}}^{\circ}\right)$, thus obtaining the following characteristic equation:

${ }^{19}$ It is easy to show that if in each country the numéraire were the tradable good, one would have

$$
\rho_{\mathrm{usGDP} t}=\theta(1-\alpha)\left(1-\tau_{\mathrm{usK}}\right)\left(L_{\mathrm{usT}}^{*}\right)^{\alpha}-1=\rho_{\mathrm{euGDP} t}=\theta(1-\alpha)\left(1-\tau_{\mathrm{euK}}\right)\left(L_{\mathrm{euT}}^{*}\right)^{\alpha}-1 \quad \text { for all } t
$$




$$
\left(\frac{1-\tau_{\mathrm{euK}}}{1-\tau_{\mathrm{usK}}}-\chi\right)\left[\frac{1}{\theta\left(1-\tau_{\mathrm{usK}}\right)}-\chi\right]\left[\frac{1}{\theta(1-\alpha)\left(1-\tau_{\mathrm{usK}}\right)}-\chi\right]=0
$$

where $\chi_{1}=\left(1-\tau_{\text {euK }}\right) /\left(1-\tau_{\text {usK }}\right), \chi_{2}=1 / \theta\left(1-\tau_{\text {usK }}\right)$ and $\chi_{3}=1 / \theta(1-\alpha)\left(1-\tau_{\text {usK }}\right)$ are the solving characteristic roots. Given that $\chi_{1}<1, \chi_{2}>1$ and $\chi_{3}>1$, one has saddle-path stability: the saddle path is the unique equilibrium trajectory of the world economy in a neighborhood of $\left(X_{\mathrm{H}}^{\circ}, Z_{\mathrm{us}}^{\circ}, L_{\mathrm{usT}}^{\circ}\right)$ since any other path satisfying (27)-(29) violates transversality or boundary conditions. Indeed, the linearized system characterizes a unique path converging to $\left(X_{\mathrm{H}}^{\circ}, Z_{\mathrm{us}}^{\circ}, L_{\mathrm{usT}}^{\circ}\right)$ :

$$
\begin{aligned}
& X_{\mathrm{H} t}-X_{\mathrm{H}}^{\circ}=m q_{11} \chi_{1}^{t} \\
& Z_{\mathrm{us} t}-Z_{\mathrm{us}}^{\circ}=m q_{21} \chi_{1}^{t} \\
& L_{\mathrm{usT} t}-L_{\mathrm{usT}}^{\circ}=m q_{31} \chi_{1}^{t}
\end{aligned}
$$

where

$$
\begin{aligned}
& m=\frac{F}{2 D}-\sqrt{\left(\frac{F}{2 D}\right)^{2}+\frac{G}{D}}<0 \\
& F \equiv\left(K_{\text {us } 0}+K_{\text {eu } 0}\right)\left\{q_{21}\left(L-L_{\text {usT }}^{\circ}\right)-Z_{\text {us }}^{\circ}-\frac{(1-\alpha)\left(1-\tau_{\text {usK }}\right)\left[\gamma(1-\mu)+\beta \mu\left(1-\tau_{\text {usL }}\right)+\varphi\right]}{(1-\tau)(1-\mu) \alpha\left(1-\tau_{\text {usL }}\right)}\right\} \\
& +K_{\text {us } 0}\left\{\left[\frac{\left(1-\tau_{\text {usK }}\right)(1-\beta) \mu}{(1-\gamma)(1-\mu)}+1\right]-q_{11}\left(L-L_{\text {usT }}^{\circ}\right)\left[\frac{\left(1-\tau_{\text {euK }}\right)(1-\beta) \mu}{(1-\gamma)(1-\mu)}+1\right]\right. \\
& \left.-\frac{q_{11} L_{\mathrm{usT}}^{\circ}(1-\alpha)\left(1-\tau_{\mathrm{euK}}\right)}{(1-\gamma)(1-\mu) \alpha}\left[\frac{\gamma(1-\mu)+\varphi}{1-\tau_{\mathrm{euL}}}+\beta \mu\right]\right\} \\
& D \equiv\left(K_{\mathrm{us} 0}+K_{\text {eu } 0}\right) q_{21}-K_{\text {us } 0} q_{11}\left\{\left[\frac{\left(1-\tau_{\text {euK }}\right)(1-\beta) \mu}{(1-\gamma)(1-\mu)}+1\right]\right. \\
& \left.-\frac{(1-\alpha)\left(1-\tau_{\mathrm{euK}}\right)}{(1-\gamma)(1-\mu) \alpha}\left[\frac{\gamma(1-\mu)+\varphi}{1-\tau_{\mathrm{euL}}}+\beta \mu\right]\right\} \\
& G \equiv\left(K_{\mathrm{us} 0}+K_{\mathrm{eu} 0}\right) Z_{\mathrm{us}}^{\circ}\left(L-L_{\mathrm{usT}}^{\circ}\right)-K_{\mathrm{us} 0}\left\{\left[\frac{\left(1-\tau_{\mathrm{usK}}\right)(1-\beta) \mu}{(1-\gamma)(1-\mu)}+1\right]\left(L-L_{\mathrm{usT}}^{\circ}\right)\right. \\
& \left.+\frac{L_{\mathrm{usT}}^{\circ}(1-\alpha)\left(1-\tau_{\mathrm{usK}}\right)}{(1-\gamma)(1-\mu) \alpha}\left[\frac{\gamma(1-\mu)+\varphi}{1-\tau_{\mathrm{usL}}}+\beta \mu\right]\right\} \\
& q_{11}=\frac{-\left[1-\theta(1-\alpha)\left(1-\tau_{\mathrm{usK}}\right)\right]}{\theta^{2}(1-\alpha)\left(1-\tau_{\mathrm{usK}}\right)^{2}\left(1-\tau_{\mathrm{euK}}\right)\left\{\begin{array}{c}
\frac{1-\theta(1-\alpha)\left(1-\tau_{\mathrm{euK}}\right)}{1-\theta(1-\alpha)\left(1-\tau_{\mathrm{usK}}\right)}\left[\frac{\left(1-\tau_{\mathrm{usK}}\right)(1-\beta) \mu}{(1-\gamma)(1-\mu)}+1\right] \\
-\left[\frac{\left(1-\tau_{\mathrm{euK}}\right)(1-\beta) \mu}{(1-\gamma)(1-\mu)}+1\right]
\end{array}\right\}}<0
\end{aligned}
$$




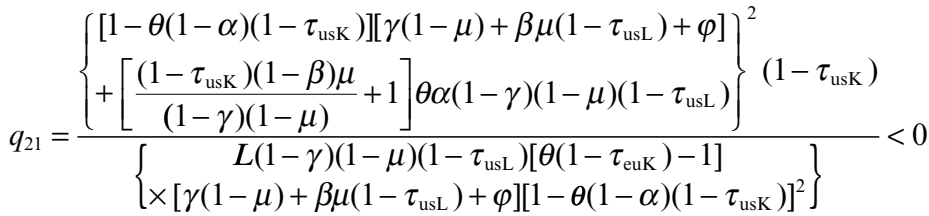

$$
\begin{aligned}
& q_{31}=1 \quad K_{\text {us } 0} \text { and } K_{\text {eu } 0} \text { given }
\end{aligned}
$$

(ii) By substituting $L_{\text {usT }}^{\circ}$ for $L_{\text {usT } t}$ and $Z_{\text {us }}^{\circ}$ for $Z_{\text {us } t+1}$ in (A17), one can verify that $\mathrm{TA}_{\text {ust }} \rightarrow 0$ as $t \rightarrow \infty$. Moreover, one can easily check in (A17) that $\mathrm{TA}_{\mathrm{us} t}<0$ whenever $L_{\text {usT } t}<L_{\text {usT }}^{\circ}$ and $Z_{\text {us } t+1}>Z_{\text {us }}^{\circ}$. Hence, a formal proof of the fact that $\mathrm{TA}_{\mathrm{us} t}<0$ for all $t<\infty$ in a neighborhood of $\left(X_{\mathrm{H}}^{\circ}, Z_{\mathrm{us}}^{\circ}, L_{\mathrm{usT}}^{\circ}\right)$ is provided by (A23) and (A24), which show that $L_{\text {usT } t}<L_{\text {usT }}^{\circ}$ and $Z_{\text {us } t+1}>Z_{\text {us }}^{\circ}$ for all $t<\infty$.

(iii) By using (1), (4), (16), (18), (20), (21), (25) and (26), one can check that $\rho_{\text {usGDP }}^{\circ}>\rho_{\text {euGDP }}^{\circ}$, where 20

$$
\rho_{i \mathrm{GDP}}^{\circ}=\lim _{t \rightarrow \infty} \rho_{i \mathrm{GDP} t}=\left[\theta(1-\alpha)\left(1-\tau_{\mathrm{iK}}\right)\left(\mathrm{L}_{i \mathrm{~T}}^{\circ}\right)^{\alpha}\right]^{1-\beta}-1
$$

\section{Proof of Proposition 3}

Under autarky, the equilibrium conditions (14) and (15) can be rewritten, respectively, as

$$
T_{i t}=K_{i t+1}
$$

and

$$
K_{i t}-K_{i \mathrm{H} t}=K_{i \mathrm{~T} t}+K_{i \mathrm{~N} t}
$$

Using (4), (A1)-(A9) and (A26)-(A27), one can derive the difference equations in $Z_{i t}$ and $L_{i \mathrm{~T} t}$ governing the equilibrium path of the $i$ economy under autarky, thus obtaining $Z_{i t+1}=f\left(Z_{i t}, L_{i \mathrm{~T} t} /\left(L-L_{i \mathrm{~T} t}\right)\right)($ see $(28))$ and

$$
\frac{L_{i \mathrm{~T} t+1}}{L-L_{i \mathrm{~T} t+1}}=h\left(\frac{L_{i \mathrm{~T} t}}{L-L_{i \mathrm{~T} t}}\right)
$$

where

$$
h(\cdot)=\frac{L_{i \mathrm{~T} t}}{\left(L-L_{i \mathrm{~T} t}\right)(1-\alpha) \theta\left(1-\tau_{i \mathrm{~K}}\right)}-\frac{\alpha(1-\mu)(1-\gamma)\left[\frac{(1-\beta)\left(1-\tau_{i \mathrm{~K}}\right) \mu}{(1-\mu)(1-\gamma)}+1\right]}{(1-\alpha)\left(1-\tau_{i \mathrm{~K}}\right)\left[\frac{(1-\mu) \gamma+\varphi}{1-\tau_{i \mathrm{~L}}}+\beta \mu\right]}
$$

\section{Given}

${ }^{20}$ It is easy to show that if in each country the numéraire were the tradable good, one would have

$$
\lim _{t \rightarrow \infty} \rho_{\mathrm{usGDP} t}=\theta(1-\alpha)\left(1-\tau_{\mathrm{usK}}\right)\left(L_{\mathrm{usT}}^{\circ}\right)^{\alpha}-1>\lim _{t \rightarrow \infty} \rho_{\mathrm{euGDP} t}=\theta(1-\alpha)\left(1-\tau_{\mathrm{euK}}\right)\left(L_{\mathrm{euT}}^{\circ}\right)^{\alpha}-1
$$




$$
\frac{\partial h\left(\frac{L_{i \mathrm{~T} t}}{L-L_{i \mathrm{~T} t}}\right)}{\partial \frac{L_{i \mathrm{~T} t}}{L-L_{i \mathrm{~T} t}}}>1 \quad \text { for all } t
$$

it turns out that the only path that satisfies (A28) and does not violate boundary conditions must be such that

$$
\frac{L_{i \mathrm{~T}}^{\bullet}}{L-L_{i \mathrm{~T}}^{\bullet}}=h\left(\frac{L_{i \mathrm{~T}}^{\bullet}}{L-L_{i \mathrm{~T}}^{\bullet}}\right) \quad \text { for all } t
$$

where ${ }^{\bullet}$ denotes the equilibrium value of a variable under autarky and

$$
L_{i \mathrm{~T}}^{\cdot}=\frac{L\left[\frac{\left(1-\tau_{i \mathrm{~K}}\right)(1-\beta) \mu}{(1-\gamma)(1-\mu)}+1\right] \theta \alpha(1-\gamma)(1-\mu)\left(1-\tau_{i \mathrm{~L}}\right)}{\left\{\begin{array}{l}
{\left[1-\theta(1-\alpha)\left(1-\tau_{i \mathrm{~K}}\right)\right]\left[\gamma(1-\mu)+\beta \mu\left(1-\tau_{i \mathrm{~L}}\right)+\varphi\right]} \\
+\left[\frac{\left(1-\tau_{i \mathrm{~K}}\right)(1-\beta) \mu}{(1-\gamma)(1-\mu)}+1\right] \theta \alpha(1-\gamma)(1-\mu)\left(1-\tau_{i \mathrm{~L}}\right)
\end{array}\right\}}
$$

If $\tau_{\text {euK }}>\tau_{\text {usK }}$ and $\tau_{\text {euL }}>\tau_{\text {usL }}$, one can check that $L_{\text {euT }}^{\bullet}<L_{\text {euT }}^{\circ}$, where $L_{\text {euT }}^{\bullet}$ and $L_{\text {euT }}^{\circ}=L_{\text {usT }}^{\circ}$ are given, respectively, by (A30) and (A21). Moreover, since also under autarky $L_{\mathrm{euH} t}$ and $L_{\mathrm{euN} t}$ are given, respectively, by (17) and (18), one can verify that $L_{\text {euT }}^{\bullet}<L_{\text {euT }}^{\circ}$ entails $L_{\text {euN }}^{\circ}>L_{\text {euT }}^{\circ}$ and $L_{\text {euH }}^{\circ}>L_{\text {euH }}^{\circ}$, which-in its turn-entails $L-L_{\text {euH }}^{\circ}<L-L_{\text {euH. }}^{\circ}$ Finally, since also under autarky one can use (1), (4), (16), (18), (20), (21), (25) and (26) to derive the equilibrium rate of GDP growth, one can check that $\rho_{\text {euGDP }}^{\circ}>\rho_{\text {euGDP }}^{\circ}$, where $\rho_{\text {euGDP }}^{\circ}$ is given by (A25) and

$$
\rho_{\mathrm{euGDP}}^{\bullet}=\lim _{t \rightarrow \infty} \rho_{\mathrm{euGDP} t}=\left[\theta(1-\alpha)\left(1-\tau_{\mathrm{euK}}\right)\left(L_{\mathrm{euT}}^{\cdot}\right)^{\alpha}\right]^{1-\beta}-1
$$

If $\tau_{\text {euK }}=\tau_{\text {usK }}$ and $\tau_{\text {euL }}>\tau_{\text {usL }}$, one can check that $L_{\text {euT }}^{\bullet}<L_{\text {euT }}^{*}$, where $L_{\text {euT }}^{\bullet}$ and $L_{\text {euT }}^{*}=L_{\text {usT }}^{*}$ are given, respectively, by (A30) and (A16). Moreover, since also under autarky $L_{\mathrm{euH} t}$ and $L_{\text {euN } t}$ are given, respectively, by (17) and (18), one can verify that $L_{\text {euT }}^{\cdot}<L_{\text {euT }}^{*}$ entails $L_{\mathrm{euN}}^{\cdot}>L_{\mathrm{euN}}^{*}$ and $L_{\mathrm{euH}}^{\cdot}>L_{\mathrm{euH}}^{*}$, which-in its turn-entails $L-L_{\mathrm{euH}}^{\cdot}<L-L_{\mathrm{euH}}^{*}$. Finally, one can check that $\rho_{\text {euGDP }}^{*}>\rho_{\text {euGDP }}^{\bullet}$, where $\rho_{\text {euGDP }}^{*}$ and $\rho_{\text {euGDP }}^{\bullet}$ are given, respectively, by (A18) and (A31).

\section{Proof of Proposition 4}

If $\tau_{\text {euK }}>\tau_{\text {usK }}$ and $\tau_{\text {euL }}>\tau_{\text {usL }}$, one has $\lim _{t \rightarrow \infty} \rho_{\text {usGDP } t}=\rho_{\text {usGDP }}^{\circ}$, where $\rho_{\text {usGDP }}^{\circ}$ is given by (A25). If the EU tax rate on capital income is cut from $\tau_{\text {euK }}$ to $\tau_{\text {euK }}^{\prime}=\tau_{\text {usK }}$, one has $\lim _{t \rightarrow \infty} \rho_{\mathrm{usGDP} t}=\rho_{\mathrm{usGDP}}^{*}$, where $\rho_{\mathrm{usGDP}}^{*}$ is given by (A18). By using (A16) and (A21), one can check that $L_{\text {usT }}^{\circ}>L_{\text {usT }}^{*}$, thus proving that $\rho_{\text {usGDP }}^{\circ}>\rho_{\text {usGDP. }}^{*}$

\section{REFERENCES}

Alcalà, F. and Ciccone, A. (2004). 'Trade and Productivity', Quarterly Journal of Economics, Vol. 119, pp. 612-645.

Alesina, A., Glaeser, E. and Sacerdote, B. (2005). 'Work and Leisure in the US and Europe: Why So Different?', NBER Macroeconomic Annual 2005, pp. 1-64. 
Barro, R. J. and Sala-i-Martin, X. (1995). Economic Growth, New York, McGraw-Hill.

Baumol, W. J. (1967). 'Macroeconomics of Unbalanced Growth: the Anatomy of Urban Crisis', American Economic Review, Vol. 57, pp. 415-426.

Baumol, W. J., Batey Blackman, S. and Wolff, E. N. (1985). 'Unbalanced Growth Revisited: Asymptotic Stagnancy and New Evidence', American Economic Review, Vol. 75, pp. 806-817.

Becker, G. S. (1965). 'A Theory of the Allocation of Time', Economic Journal, Vol. 75, pp. 493-517.

Benhabib, J., Rogerson, R. and Wright, R. (1991). 'Homework in Macroeconomics: Household Production and Aggregate Fluctuations', Journal of Political Economy, Vol. 99, pp. 1166-1187.

Bonatti, L. and Felice, G. (2008). 'Endogenous Growth and Changing Sectoral Composition in Advanced Economies', Structural Change and Economic Dynamics, Vol. 19, pp. 109-131.

Burda, M. C., Hamermesh, D. S. and Weil, P. (2006). 'Different but Equal: Total Work, Gender and Social Norms in EU and US Time Use', Paper prepared for the Annual Conference of the Fondazione Rodolfo Debenedetti, Portovenere, Italy, 27 May.

D'Agostino, A., Serafini, R. and Ward-Warmedinger, M. (2006). 'Sectoral Explanations of Employment in Europe. The Role of Services', ECB Working Paper Series 625, European Central Bank.

Davis, S. J. and Henrekson, M. (2004). 'Tax Effects on Work Activity, Industry Mix and Shadow Economy Size: Evidence from Rich-country Comparisons', NBER Working Paper 10509, National Bureau of Economic Research.

Echevarria, C. (1997). 'Changes in Sectoral Composition Associated with Economic Growth', International Economic Review, Vol. 38, pp. 431-452.

European Commission (1999). Employment in Europe 1999, Luxembourg, Office for Official Publications of the European Communities.

Frankel, M. (1962). 'The Production Function in Allocation and Growth: a Synthesis', American Economic Review, Vol. 52, pp. 995-1022.

Freeman, R. B. and Schettkat, R. (2005). 'Marketization of Household Production and the EU-US Gap in Work', Economic Policy, Vol. 20, No. 41, pp. 650 .

Kongsamut, P., Rebelo, S. and Danyang, X. (2001). 'Beyond Balanced Growth', Review of Economic Studies, Vol. 68, pp. 869-882.

Mann, C. L. (2004). 'The US Current Account, New Economy Services, and Implications for Sustainability', Review of International Economics, Vol. 12, pp. 262 276.

McGratten, E. R., Rogerson, R. and Wright, R. (1997). 'An Equilibrium Model of the Business Cycle with Household Production and Fiscal Policy', International Economic Review, Vol. 38, pp. 267-290.

Ngai, R. and Pissarides, C. (2007). 'Structural Change in a Multi-sector Model of Growth', American Economic Review, Vol. 97, pp. 429-443.

Obstfeld, M. and Rogoff, K. (1996). Foundations of International Macroeconomics, Cambridge, MA, MIT Press.

Olovsson, C. (2004). 'Why do Europeans Work So Little?', Institute for International Economic Studies Seminar Paper 727, Stockholm University.

Parente, S., Rogerson, R. and Wright, R. (2000). 'Homework in Development Economics: Household Production and the Wealth of Nations', Journal of Political Economy, Vol. 108, pp. 680-687. 
Pollak, R. A. and Wachter, M. L. (1975). 'The Relevance of the Households Production Function and Its Implications for the Allocation of Time', Journal of Political Economy, Vol. 83, pp. 255-277.

Prescott, E. C. (2004). 'Why do Americans Work So Much More than Europeans?', Federal Reserve Bank of Minneapolis Quarterly Review, Vol. 28, No. 1, pp. 2-13.

Ragan, K. S. (2005). 'Taxes, Transfers and Time Use: Fiscal Policy in a Household Production Model', Mimeo, University of Chicago.

Rogerson, R. (2005). 'Structural Transformation and the Deterioration of European Labor Market Outcomes', Mimeo, Arizona State University. 